\title{
Spatial-Temporal Features of Wuhan Urban Agglomeration Regional Development Pattern-Based on DMSP/OLS Night Light Data
}

\author{
Mengjie Zhang ${ }^{1 *}$, Wenwei Miao ${ }^{1}$, Yingpin Yang ${ }^{2}$, Chong Peng${ }^{1}$, Yaping Huang ${ }^{1}$ \\ ${ }^{1}$ School of Architecture and Urban Planning, Huazhong University of Science and Technology, Wuhan, China \\ ${ }^{2}$ Institute of Remote Sensing and Digital Earth, Chinese Academy of Sciences, Beijing, China \\ Email: *dreamthought0530@163.com
}

How to cite this paper: Zhang, M.J., Miao, W.W., Yang, Y.P., Peng, C. and Huang, Y.P. (2017) Spatial-Temporal Features of Wuhan Urban Agglomeration Regional Development Pattern-Based on DMSP/OLS Night Light Data. Journal of Building Construction and Planning Research, 5, 14-29. https://doi.org/10.4236/jbcpr.2017.51002

Received: February 3, 2017

Accepted: March 5, 2017

Published: March 8, 2017

Copyright (c) 2017 by authors and Scientific Research Publishing Inc. This work is licensed under the Creative Commons Attribution International License (CC BY 4.0).

http://creativecommons.org/licenses/by/4.0/

\section{(c) (i) Open Access}

\begin{abstract}
Based on the night light data, urban area data, and economic data of Wuhan Urban Agglomeration from 2009 to 2015, we use spatial correlation dimension, spatial self-correlation analysis and weighted standard deviation ellipse to identify the general characteristics and dynamic evolution characteristics of urban spatial pattern and economic disparity pattern. The research results prove that: between 2009 and 2013, Wuhan Urban Agglomeration expanded gradually from northwest to southeast and presented the dynamic evolution features of "along the river and the road". The spatial structure is obvious, forming the pattern of "core-periphery". The development of Wuhan Urban Agglomeration has obvious imbalance in economic geography space, presenting the development tendency of "One prominent, stronger in the west and weaker in the east". The contract within Wuhan Urban Agglomeration is gradually decreased. Wuhan city and its surrounding areas have stronger economic growth strength as well as the cities along The Yangtze River. However, the relative development rate of Wuhan city area is still far higher than other cities and counties.
\end{abstract}

\section{Keywords}

Night Light Data, Urban Spatial Pattern, Economic Disparity Pattern, Wuhan Urban Agglomeration

\section{Introduction}

Urban agglomeration is an area where the economy, politics, culture and system are highly integrated, and its formation and development process is affected by the space, economy, society and multiple factors. Therefore, the research on the 
regional development pattern of urban agglomeration not only pays attention to its visual development pattern, but also focuses on the potential economic geographic pattern, namely, differentiation pattern inside the urban agglomeration. At present, the research on the spatial pattern of the urban agglomeration has changed from mainly relying on qualitative analysis to the comprehensive analysis combining qualitative and quantitative analysis [1] [2] [3]. However, it is difficult for the single statistical index to make a comprehensive characterization of the spatial development of urban agglomeration, and it is in urgent need of expanding the new methodology and new data sources. DMSP/OLS night light data acquired by American military meteorological satellite DMSP cover the in formation closely related to the distribution of population, city, economy and other factors and realize the organic integration of single statistical index with the comprehensive index system. Compared to the traditional remote sensing data and statistical data, these are available, intuitive and comprehensive and are applicable to the research on the spatial development pattern of urban agglomeration.

The research carried out through the night light data are mainly centered on the urbanization extension [4] [5] [6] [7], economic and population estimate [8] [9] [10], carbon emission [11], light pollution and other aspects [12]. Wang Yueyun, Liao Bing, et al. use the light data to extract the urban construction land and carry out the empirical research in Jiangsu Province and Jiangxi Province by establishing the urban construction land extension form evaluation index [13] [14]; Xu Mengjie, et al. establish the spatial pattern of the Yangtze River Delta with the night light data reconstruction [15], and Chang Ting, et al. carry out the analysis and research on the spatial and temporal process and characteristics of the Yangtze River Delta urban agglomerations during the urban expansion in recent 10 years [16]; Shen Tiyan, et al. make the analysis on the spatial structure of urban system in the Yangtze River Economic Zone and its evolution characteristics [17]. The author holds that the comprehensive consideration shall be made from two aspects-space and economy to make the comprehensive and accurate research on the regional development pattern of urban agglomeration. The night light data are the new data source. The application objects should not only include the state-level areas and urban agglomerations, but also cover the regional-level and prefecture-level urban agglomerations, thus verifying the applicability of data in the different scale space and enriching the achievements of empirical application research. Therefore, this paper selected Wuhan urban agglomeration as the research object, carried out the investigation at the county-level space with the night light data and economic statistical data, made intuitive recognition of urban spatial pattern, and deeply analyzed the economic difference pattern.

\section{Data Source and Research Method}

\subsection{Research Area}

Wuhan urban agglomeration covers Wuhan and its 9 surrounding cities includ- 
ing Huangshi, Ezhou, Xiaogan, Huanggang, Xianning, Xiantao, Tianmen and Qianjiang within the range of about 100 kilometers of radius, with the area of $58,052 \mathrm{~km}^{2}$, which is commonly known as " $1+8$ urban circle". Upon the investigation at the county (provincial directly governing city, county-level city and district) level, Wuhan urban agglomeration includes 39 basic spatial units.

\subsection{Data Acquisition and Processing}

The data used by the research are mainly remote sensing data (night light data), statistical data and auxiliary GIS data. Among them, night light data are from the website of the National Geophysics Data Center which cover the night light remote sensing images from 1999 to $2013^{1}$. The basic data used by the research are the stable light image data which are obtained through the direct averaging processing of VNIR channel gray value throughout the year after the influences from the cloud, flame and other occasional noises are removed The scope of data gray value is $1-63$, and spatial resolution is $1 \mathrm{~km}$. This paper selected 2009-2013 Wuhan urban agglomeration night light influence as the research data.

Since the light has the overflow characteristic, the light should be within the boundary range of the real built-up area through the processing in the process of using the night light data to extract the urban built-up area. The process is data acquisition (stable data)-threshold setting (data selection)-superposition of administrative boundaries (data approval)-final data. The specific method is setting the initial threshold of night lighting intensity, making statistics of light plaque area of each spatial unit, and comparing them with the built-up area until the land-use area of built-up area extracted by light data under a threshold condition is sufficiently close to the statistical data. Since DN (remote sensing image pixel brightness value) is $<=63$, the initial threshold is 40 , and the threshold of different cities in different years is different, with 2013 spatial information extraction threshold as an example (Table 1).

\subsection{Research Method}

\subsubsection{Spatial Structure Correlation Analysis}

The urban spatial structure correlation fractal research generally uses the correlation dimension to scale, with the formula as follows:

$$
\begin{aligned}
& C(r)=\frac{1}{N^{2}} \sum_{i, j=1}^{N} H\left(r-d_{i j}\right), i \neq j \\
& H\left(r-d_{i j}\right)=\left\{\begin{array}{l}
1,\left(d_{i j} \leq r\right) \\
0\left(d_{i j}>r\right)
\end{array} C(r) \propto r^{D}\right.
\end{aligned}
$$

where: $r$ is the selected distance; $d_{i j}$ is the straight distance between City $i$ and City $j$ within the urban system; $H$ is Heaviside function; $D$ is the spatial correlation dimension, whose numerical range of spatial correlation dimension $D$ is 0 2. When $\mathrm{D}$ approaches to 0 , it indicates that urban distribution height is concentrated in a primate city; When $D$ approaches to 2 , it indicates that the urban

${ }^{1}$ There is only 15 years of data open to public currently. 
Table 1. Spatial information threshold of Wuhan urban agglomeration based on DMSP/ OLS data in 2013.

\begin{tabular}{ccccc}
\hline City & Threshold & Extraction area $\left(\mathrm{km}^{2}\right)$ & Statistical area $\left(\mathrm{km}^{2}\right)$ & Relative error (\%) \\
\hline Wuhan & 62 & 514 & 534 & -0.0375 \\
Huangshi & 53 & 78 & 88 & -0.1136 \\
Daye & 56 & 18 & 27 & -0.3333 \\
Ezhou & 51 & 77 & 60 & 0.2833 \\
Huanggang & 53 & 50 & 47 & 0.0638 \\
Macheng & 48 & 27 & 27 & 0 \\
Wuxue & 48 & 23 & 24 & -0.0417 \\
Xiaogan & 51 & 63 & 62 & 0.0161 \\
Yingcheng & 47 & 46 & 46 & 0 \\
Anlu & 47 & 22 & 22 & 0 \\
Hanchuan & 47 & 26 & 26 & 0 \\
Xianning & 49 & 74 & 72 & 0.0278 \\
Chibi & 49 & 28 & 26 & 0.0769 \\
Xiantao & 45 & 67 & 67 & 0.0125 \\
Tianmen & 42 & 79 & 80 & 0.10 \\
Qianjiang & 50 & 55 & 50 & \\
\hline & & & & 0 \\
\hline
\end{tabular}

spatial distribution aggregation is not significant, and correlation function is weak; When $D$ approaches to 1 , it indicates that the urban spatial concentration presents the linear distribution along the railway, highway, river and other axes [18].

\subsubsection{Urban Spatial Evolution Process Analysis}

To measure the urban spatial evolution of Wuhan urban agglomeration in 5 years, the standard deviation elliptical figure can be made. The ellipse center reflects the relative position and change of core of factor spatial layout; Long axis and short axis of the ellipse characterize the dispersion degree of factor spatial layout in the primary and secondary direction respectively. The rotation angle reflects the main trend direction of its distribution; The area of the ellipse characterizes the concentration or dispersion degree of factor spatial distribution [19]. The standard deviation ellipse of different years can be used to observe the dynamic characteristics of core, denseness, direction and form of discrete data changing along with the time in the spatial distribution [20].

\subsubsection{Economic Difference Spatial Pattern Analysis}

1) Coefficient of Variable is used to measure the relative difference level of regional economic development.

$$
C V=\frac{S}{\bar{Y}}=\frac{1}{\bar{Y}} \sqrt{\frac{\sum_{i=1}^{n}\left(Y_{i}-\bar{Y}\right)^{2}}{n}}
$$


2) The global and local spatial auto-correlation analyses were used to identify the static and dynamic pattern characteristics of the economic geography of Wuhan urban agglomeration.

(1) The global Moran's I index can be used to measure the spatial correlation and spatial difference degree among regions. Moran's I value is between -1 and 1. The value more than 0 indicates the positive correlation, while the value less than 0 indicates the negative correlation. If the value is larger, the spatial distribution correlation is more significant. What's more, the value approaching to 0 indicates that the spatial distribution presents the random distribution.

(2) LISA (Local Indicators of Spatial Association) analysis can measure the correlation of the regional spatial units, and conclude the spatial agglomeration area.

\section{Results and Analyses}

\subsection{Urban Spatial Pattern}

\subsubsection{General Characteristics}

According to the original night light image map (Figure 1) of Wuhan urban agglomeration from 2009 to 2013, the light pixel brightness and density increase year by year, which is embodied in the constant increase of spatial activity intensity. The overall urban spatial distribution of Wuhan urban agglomeration presents the core-edge structure with relatively dense core and relatively sparse edge. Wuhan and Xianning, Xiaogan, Ezhou and Huangshi gradually gather into the core urban concentration area. Meanwhile, the surrounding space joints also develop constantly and form several sub-regional spaces, presenting the radial core urban concentration area.

According to the spatial correlation dimension model in the research method, the distance among spatial units of urban agglomeration is established into $39^{\star} 39$ matrix (due to the limited length, the original matrix data are omitted) ${ }^{2}$. To facilitate the processing, the Formula (3) can be used to select yardstick r,

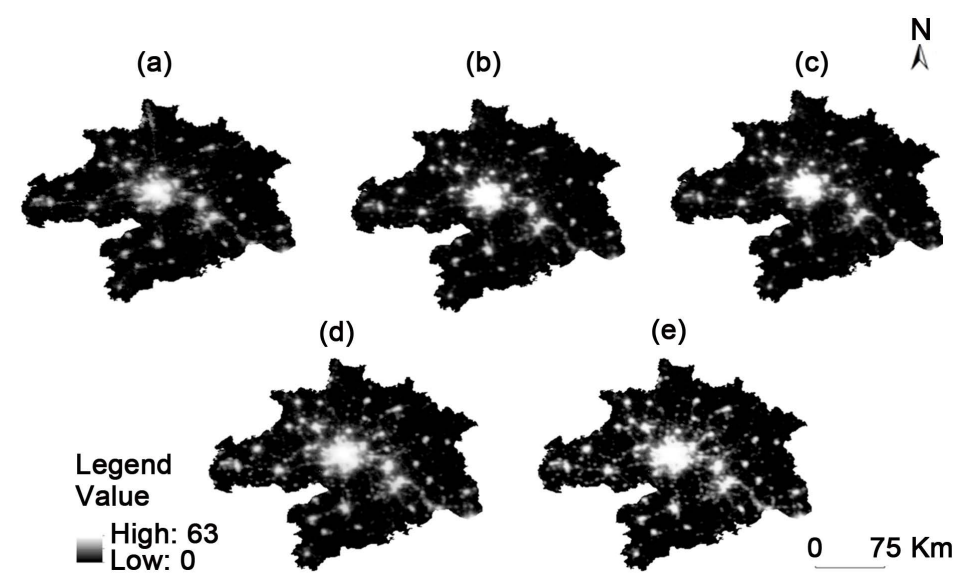

Figure 1. The night light image of Wuhan Urban Agglomeration from 2009 to 2013. (a) 2009; (b) 2010; (c) 2011; (d) 2012; (e) 2013.

${ }^{2}$ The linear distance of two palces is calculated by Google map. 
with scale $\Delta r=15$, and a series of dot pair $(r, N(r))$ are generated (as shown in Table 2).

$$
N(r) \propto r^{D} N(r)=\sum_{i, j=1}^{N} H\left(r-d_{i j}\right), i \neq j
$$

Dot pair (r, N(r)) is made into double logarithmic coordinate graph, the firstorder function is used to make linear fitting [21] [22] of dot pair $(\mathrm{r}, \mathrm{N}(\mathrm{r})$ ), with the results as shown in Figure 2. The regression calculation of sequence point is made to obtain $\mathrm{D}$ value 1.230 and coefficient of determination $\mathrm{R}^{2}=0.9646$. A smaller $\mathrm{D}$ value indicates that the entire spatial association of Wuhan urban agglomeration is more close, while $\mathrm{D}$ value approaching to 1 indicates that the urban space of Wuhan urban agglomeration has the characteristics of linear distribution.

In order to further verify the calculation results, this paper carried out the superposition of 2013 Wuhan urban agglomeration nigh light image map with the line of the first-order river, main railway and highway (Figure 3), and found out that the urban spatial develop of Wuhan urban agglomeration has the characteristic of shaft-driven linear expansion "along river" and "along road". As the central city of urban agglomeration, Wuhan is roughly located in the central position of urban groups. Starting from Wuhan, many radial axes will be formed and connect all cities; There is riverside transportation corridor eastwards connecting Ezhou, Huangshi, Huanggang and other cities; There is Beijing-Guangzhou transportation corridor northwards connecting Xiaogan, Yingcheng,

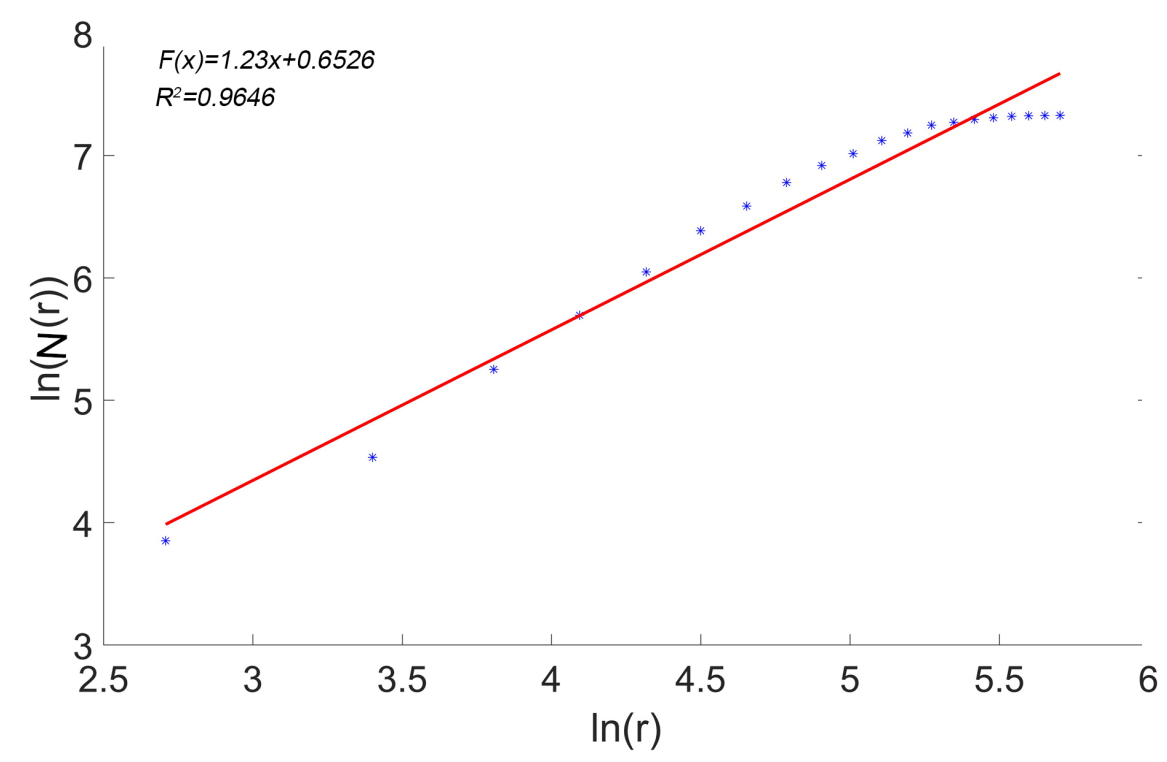

Figure 2. The ln-ln plot.

Table 2. $r$ and "Selected" distance number $N(r)$.

\begin{tabular}{ccccccccccccccccccccc}
\hline No. & 1 & 2 & 3 & 4 & $\mathbf{5}$ & $\mathbf{6}$ & $\mathbf{7}$ & $\mathbf{8}$ & $\mathbf{9}$ & 10 & $\mathbf{1 1}$ & $\mathbf{1 2}$ & $\mathbf{1 3}$ & 14 & 15 & 16 & 17 & 18 & 19 & 20 \\
\hline$r$ & 15 & 30 & 45 & 60 & 75 & 90 & 105 & 120 & 135 & 150 & 165 & 180 & 195 & 210 & 225 & 240 & 255 & 270 & 285 & 300 \\
$N(r)$ & 47 & 93 & 191 & 297 & 423 & 593 & 725 & 879 & 1011 & 1113 & 1239 & 1317 & 1405 & 1439 & 1473 & 1493 & 1511 & 1517 & 1519 & 1521 \\
\hline
\end{tabular}




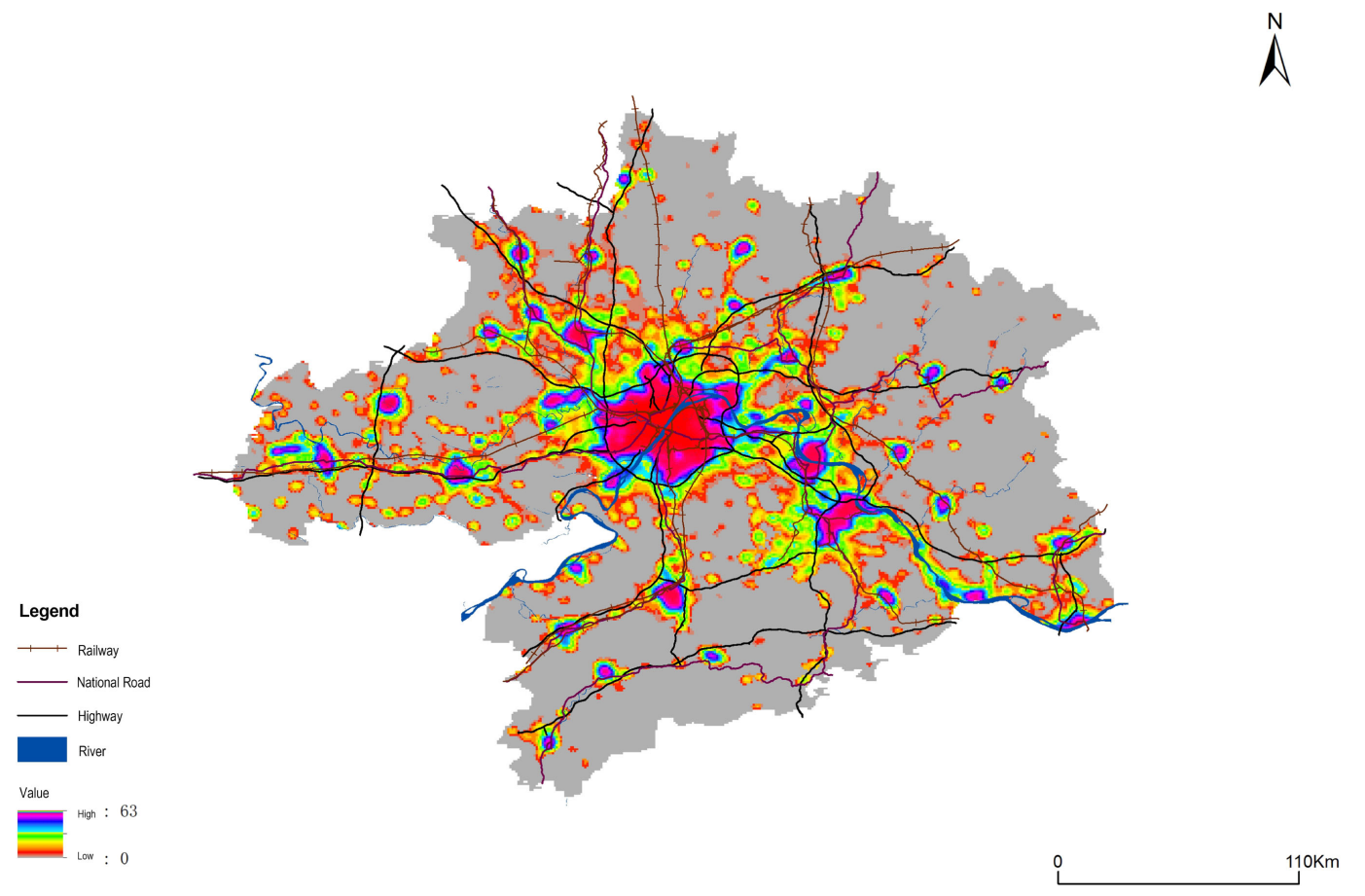

Figure 3. The night light image of Wuhan Urban Agglomeration in 2013 with the main river, railway and highway.

Yunmeng, Dawu and other cities; There is Wuhan-Yichang transportation corridor westwards connecting three cities, "Xiantao, Tianmen and Qianjiang"; There is Wuhan-Xianning transportation corridor southwards connecting Xianning and Changsha-Zhuzhou-Xiangtan urban agglomeration; There is Shanghai-chengdu transportation corridor northeastwards connecting Macheng and other cities in Dabieshan area; There is Wuhan-Shiyan transportation corridor connecting Xiangyang, Shiyan and other cities.

\subsubsection{Dynamic Evolution Characteristics}

According to the built-up area of each spatial unit of Wuhan urban agglomeration extracted by 2009-2013 night light data, this paper analyzed the urban spatial change of Wuhan urban agglomeration in 5 years. The area of built-up area of Wuhan urban agglomeration in 5 years is $1004 \mathrm{~km}^{2}, 1096.1 \mathrm{~km}^{2}, 1153 \mathrm{~km}^{2}$, $1189.5 \mathrm{~km}^{2}$ and $1258 \mathrm{~km}^{2}$ respectively, and urban space presents the trend of expanding year by yea [23]. Compared to the area of built-up area of 2009 and 2013, the growth range is not large.

In order to further measure and find out the spatial direction of the urban spatial change of Wuhan urban agglomeration, GIS was used to draw the standard deviation ellipse and changing track of core (Figure 4) of the urban space of Wuhan urban agglomeration in 5 years. In these 5 years, the ellipse area of Wuhan urban agglomeration increases from $64,773.758731 \mathrm{~km}^{2}$ in 2009 to $81,235.313993 \mathrm{~km}^{2}$ in 2013. There is a certain increase in both long axis and short axis direction, and the increase in the short axis direction is more significant (Table 3); The core of urban agglomeration has the local fluctuations, but it 


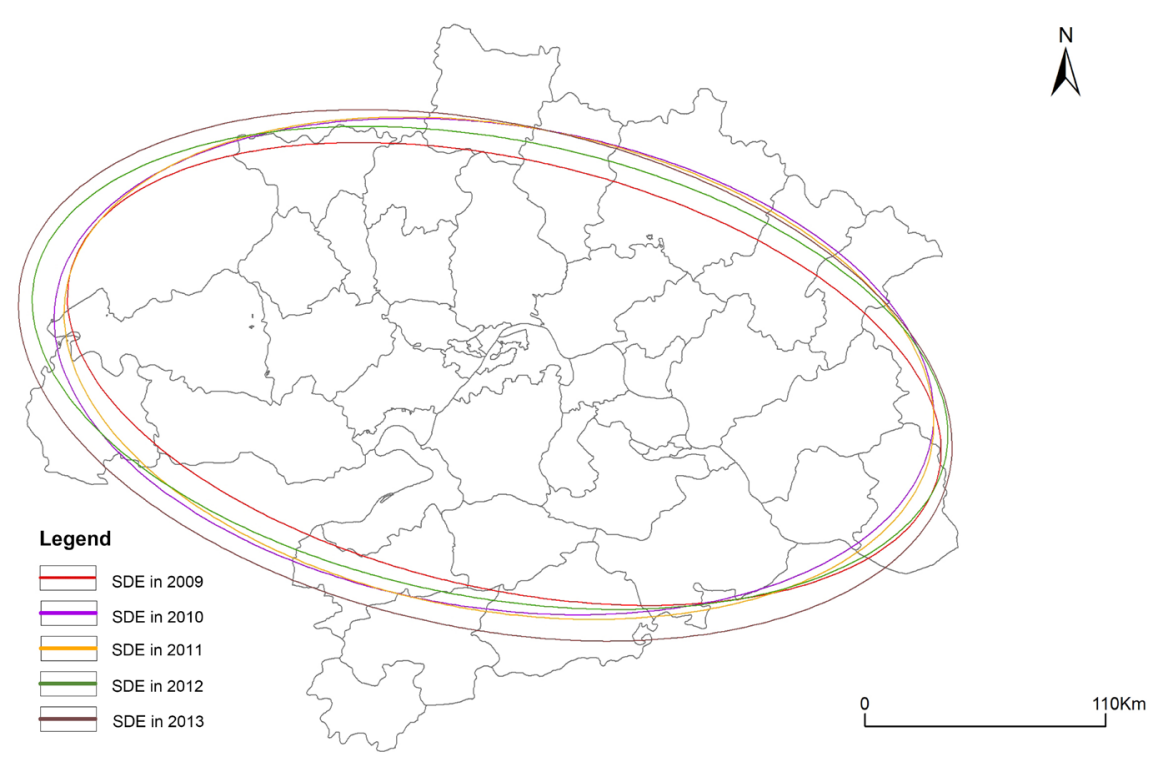

Figure 4. Standard deviation ellipse from 2009 to 2013

Table 3. Variation of standard deviation ellipse parameters from 2009 to 2013.

\begin{tabular}{ccccccc}
\hline Year & $\begin{array}{c}\text { Xcoordinates } \\
\text { of the center }\end{array}$ & $\begin{array}{c}\text { Y coordinates } \\
\text { of the center }\end{array}$ & $\begin{array}{c}\text { Major } \\
\text { axis }(\mathrm{km})\end{array}$ & $\begin{array}{c}\text { Minor } \\
\text { axis }(\mathrm{km})\end{array}$ & Area $\left(\mathrm{km}^{2}\right)$ & $\begin{array}{c}\text { Rotation } \\
\text { Angle }\end{array}$ \\
\hline 2009 & 114.364638 & 30.499724 & 1.732796 & 0.831513 & 64773.758731 & 102.917663 \\
2010 & 114.324228 & 30.528621 & 1.724956 & 0.937511 & 72724.104855 & 98.839757 \\
2011 & 114.344102 & 30.522232 & 1.711087 & 0.940554 & 72368.1725275 & 100.35413 \\
2012 & 114.309468 & 30.523268 & 1.805727 & 0.888247 & 72123.789934 & 101.001741 \\
2013 & 114.290524 & 30.494316 & 1.844574 & 0.979664 & 81235.313993 & 101.919305 \\
\hline
\end{tabular}

is still located in the urban area of Wuhan. It mainly presents the westward shifting in the longitude direction and the fluctuation in the latitude direction. It indicates that the entire spatial development of Wuhan urban agglomeration presents the characteristics of first moving towards northwest and then towards southwest. The spatial growth is mainly concentrated on the western cities.

\subsection{Economic Difference Pattern}

\subsubsection{General Characteristics}

The night light data can synthetically characterize the breadth and intensity of human activity and is closely related to the urban economic factor. Therefore, this paper makes the spatial visualization of the night lighting intensity vector data of each spatial unit on the GIS platform (Figure 5). The overall development of Wuhan urban agglomeration has the difference and imbalance in the economic geographic space and presents the development trend of "stronger in the west than the east".

In order to further know the economic difference pattern of Wuhan urban agglomeration, in combination with GDP, per capita GDP, social fixed investment assets and total social consumable retail sales data of Wuhan urban agglomera- 
(a)

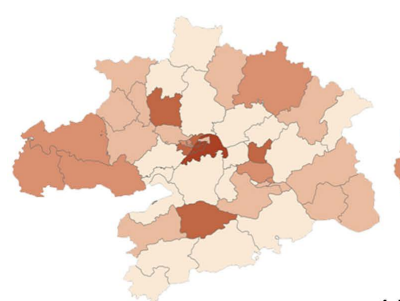

(d)

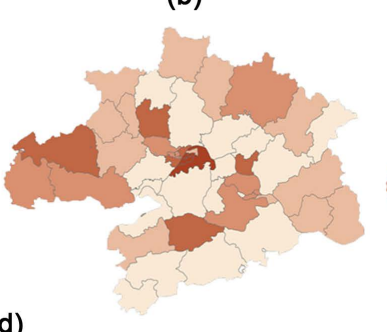

(c)

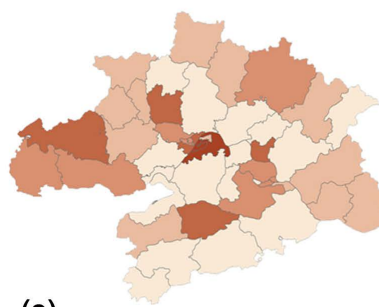

(e)
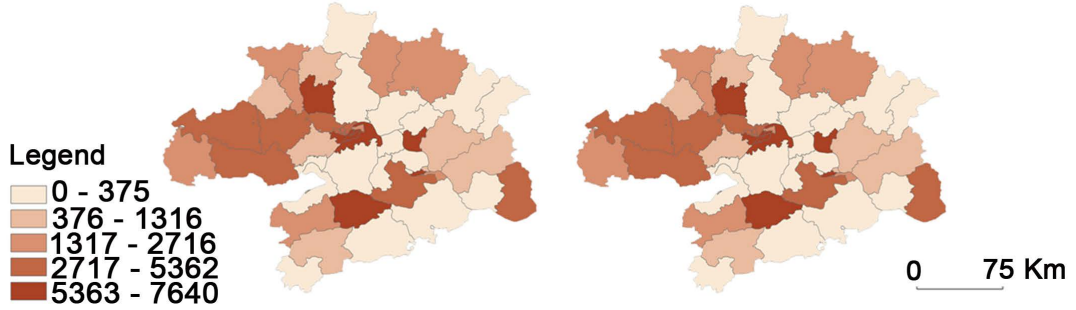

Figure 5. The night light geographical distribution map of Wuhan Urban Agglomeration from 2009 to 2013. (a) 2009; (b) 2010; (c) 2011; (d) 2012; (e) 2013.

tion counties (districts) in 2015 (Figure 6). Upon the comprehensive judgment of analysis results, the development of Wuhan urban agglomeration is very unbalanced. Wuhan has the significant polarization, with developed economic areas locating in Wuhan municipal district and Wuhan-Ezhou-Huangshi-Huanggang urban concentration area and economically backward areas locating in the east (southeast and northeast) of Wuhan urban agglomeration.

\subsubsection{Dynamic Change Characteristics}

This paper selected GDP data of various cities and counties of Wuhan urban agglomeration in 2009 and 2015, calculated the average annual growth rate and relative development rate $(\mathrm{NICH})^{3}$ of GDP, made the quantitative analysis and spatial visualization based on ArcGIS platform (Figure 7).

In terms of average annual growth rate, the regions with faster development speed from 2009 to 2015 of Wuhan urban agglomeration are mainly concentrated on the central part and neighboring cities and counties of Wuhan, but Wuhan municipal district with larger economic aggregate doesn't display the outstanding development speed; In addition, due to the limited topographic conditions, the development speed of Dawu County, Xiaochang County, Yingshan County, Luotian County and other regions is slower.

In terms of relative development rate, the regions with better economic growth ability are still in the middle part of Wuhan urban agglomeration, and the growth ability of Wuhan municipal district is especially outstanding and its role in driving the surrounding hinterland areas is also quite significant. Cities along the Yangtze River area such as Qianjiang, Xiantao, Hanchuan, etc. also have better economic growth ability; The northern, eastern and southern parts of Wuhan city circle have the poorer economic growth ability.

${ }^{3}$ The ratio of GDP in each spatial unit to $\mathrm{GDP}$ of the whole region in a given period of time. 


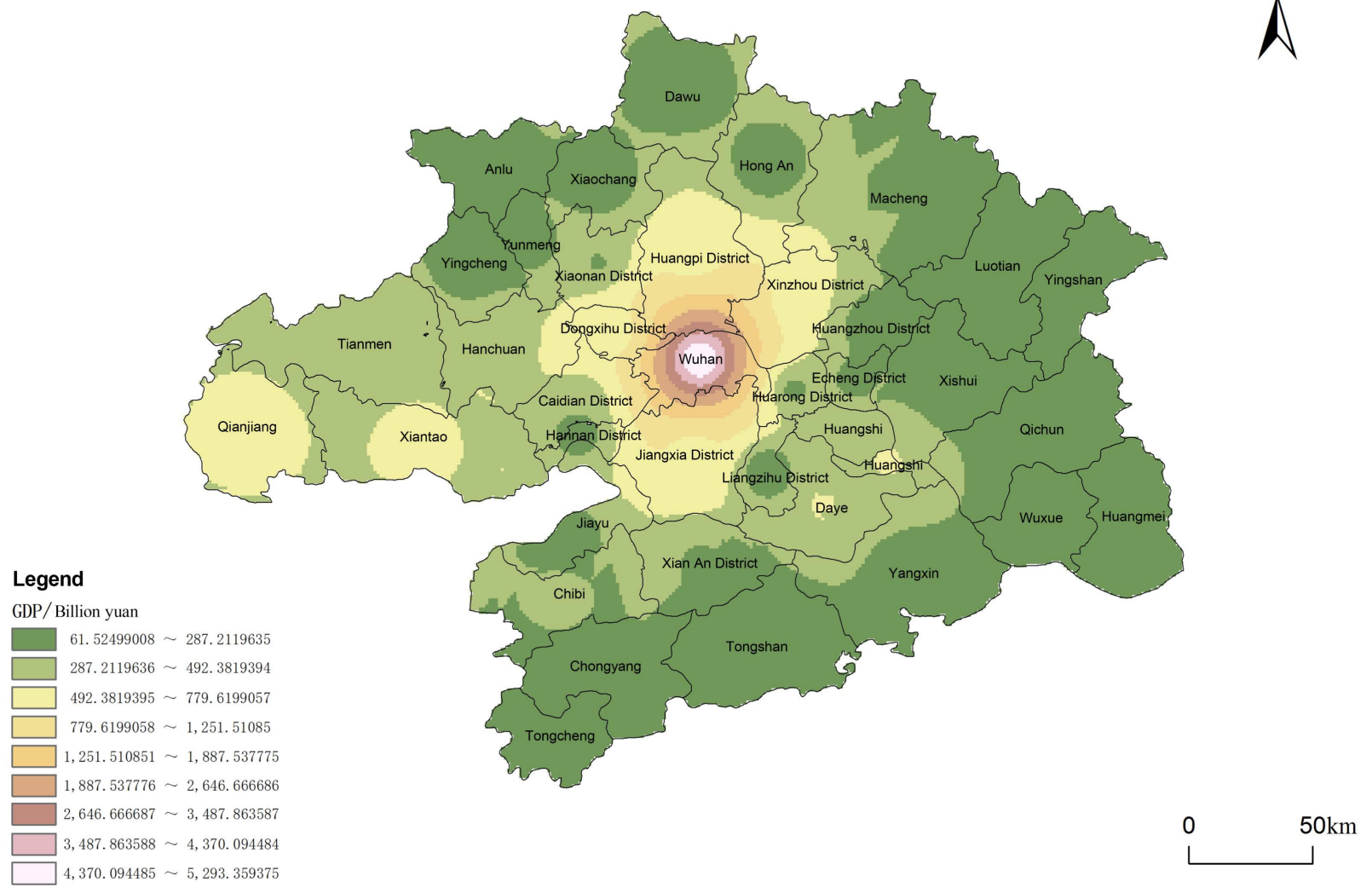

\section{Legend}

GDP/Billion yuan
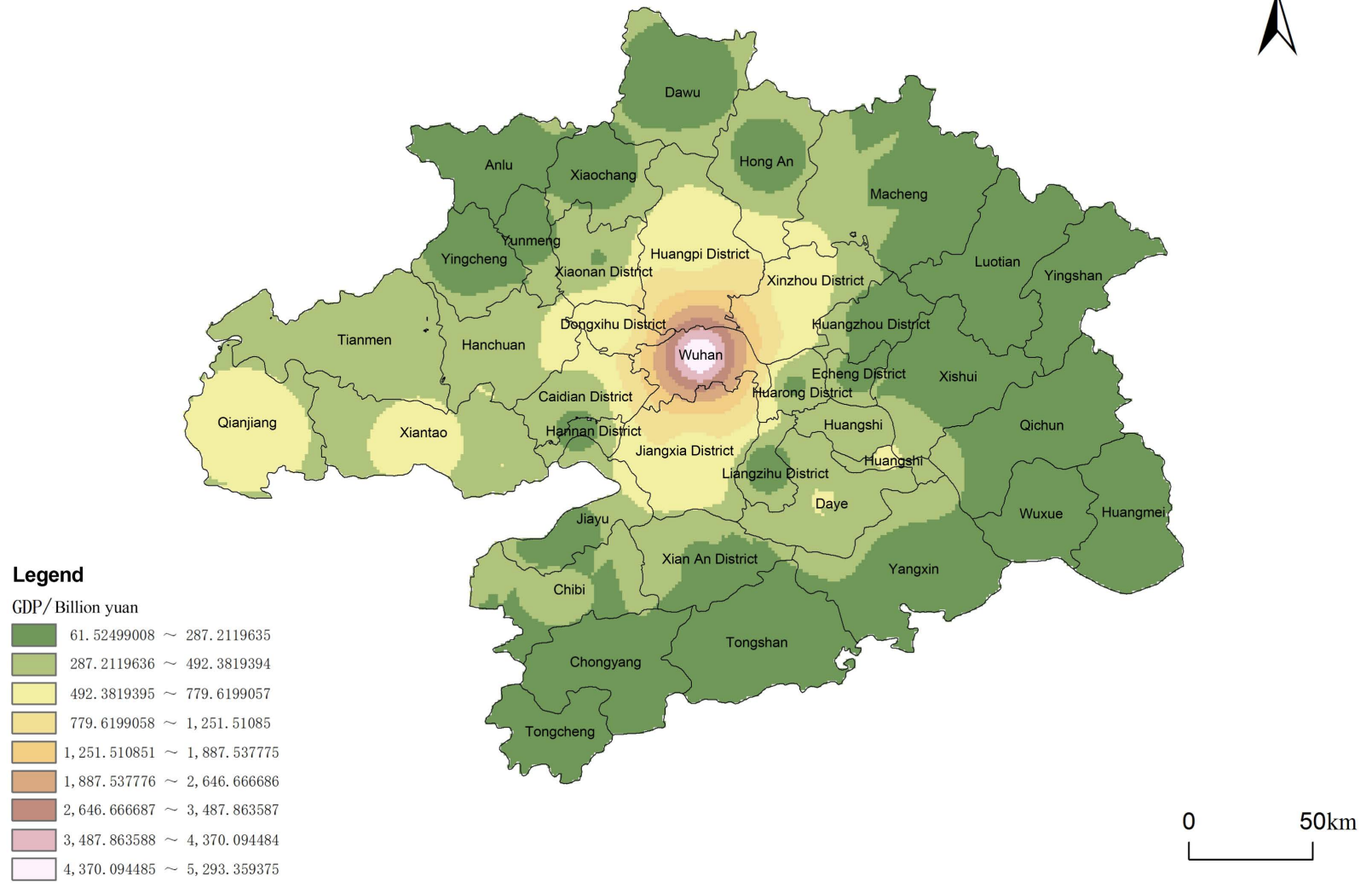

A

(a)

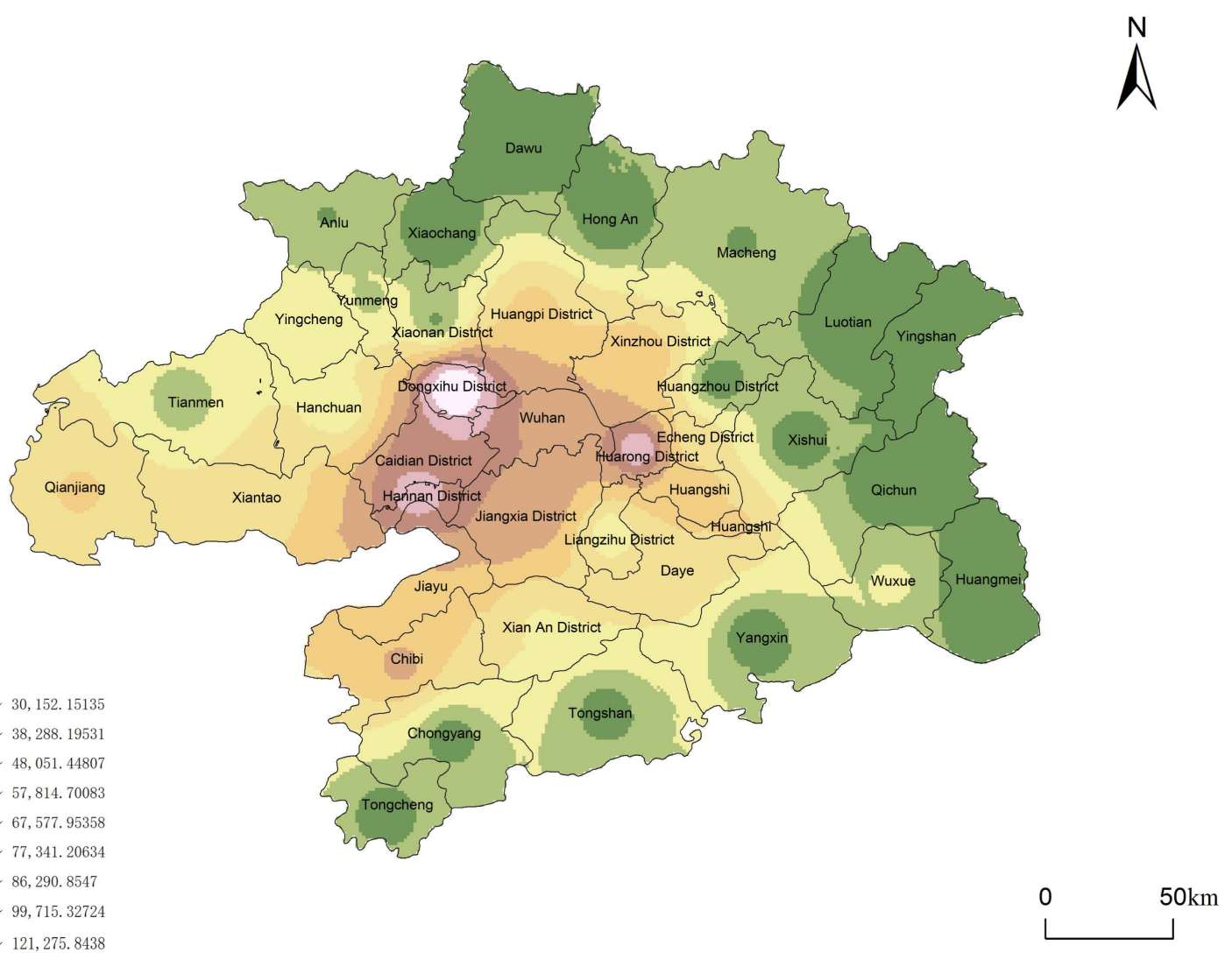

\section{Legend}

\section{Per capita GDP/yuan}

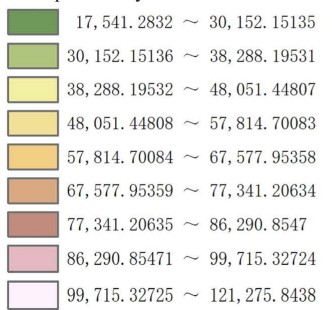

(b) 


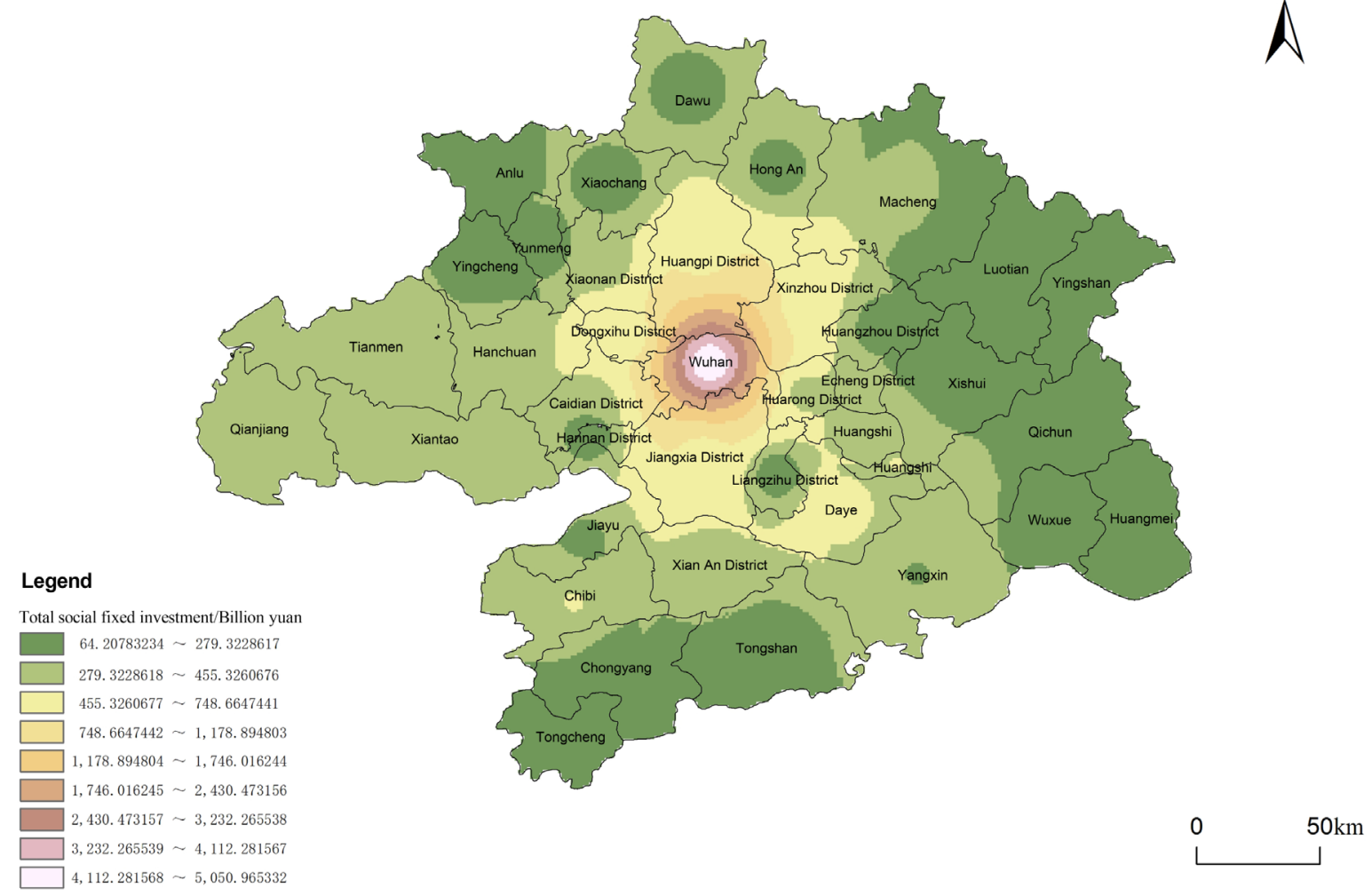

(c)

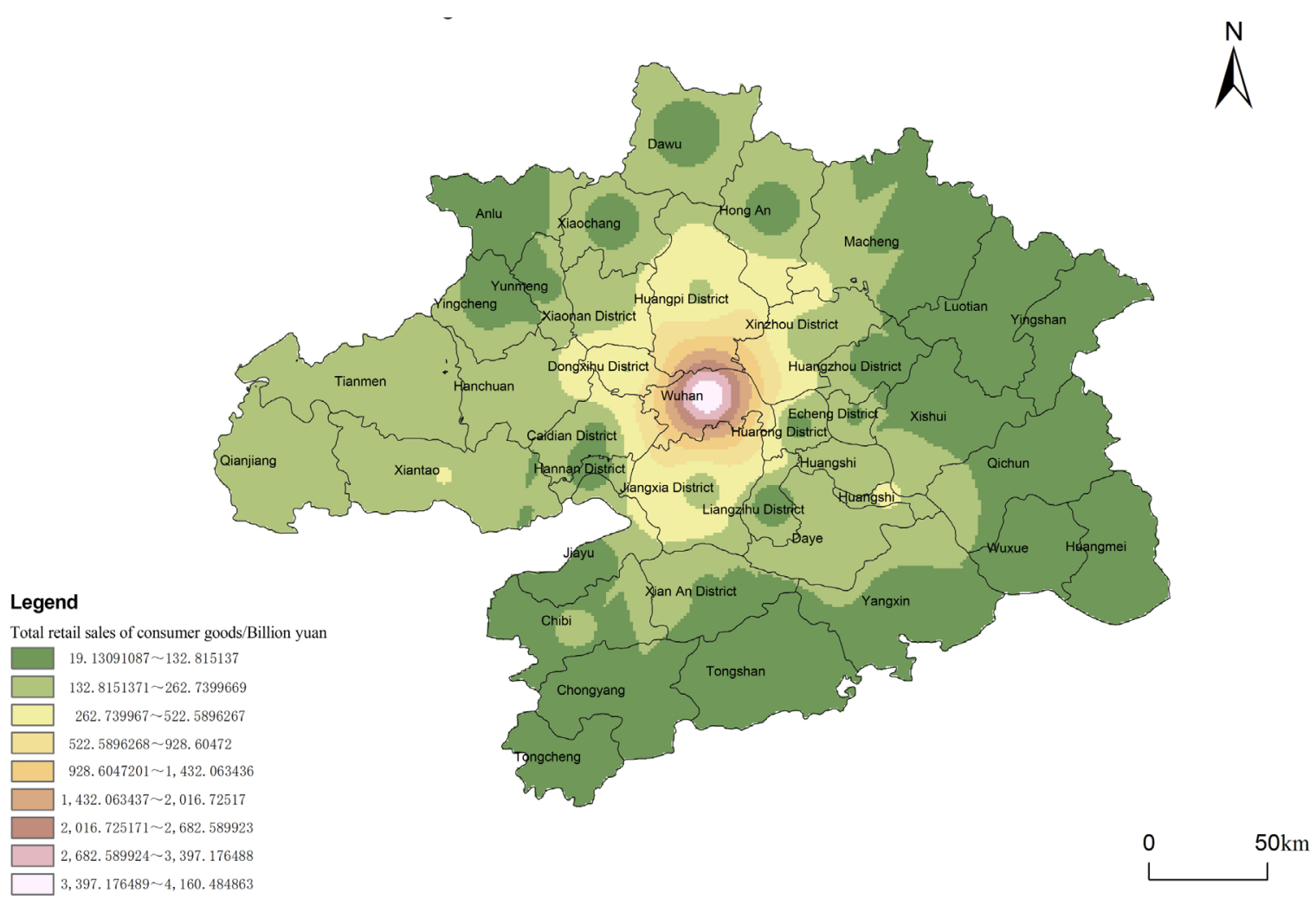

(d)

Figure 6. Spatial-economic geography pattern of Wuhan Urban Agglomeration based on spatial interpolation method. (a) GDP; (b) Per capita GDP; (c) Total social fixed investment; (d) Total retail sales of consumer goods. 


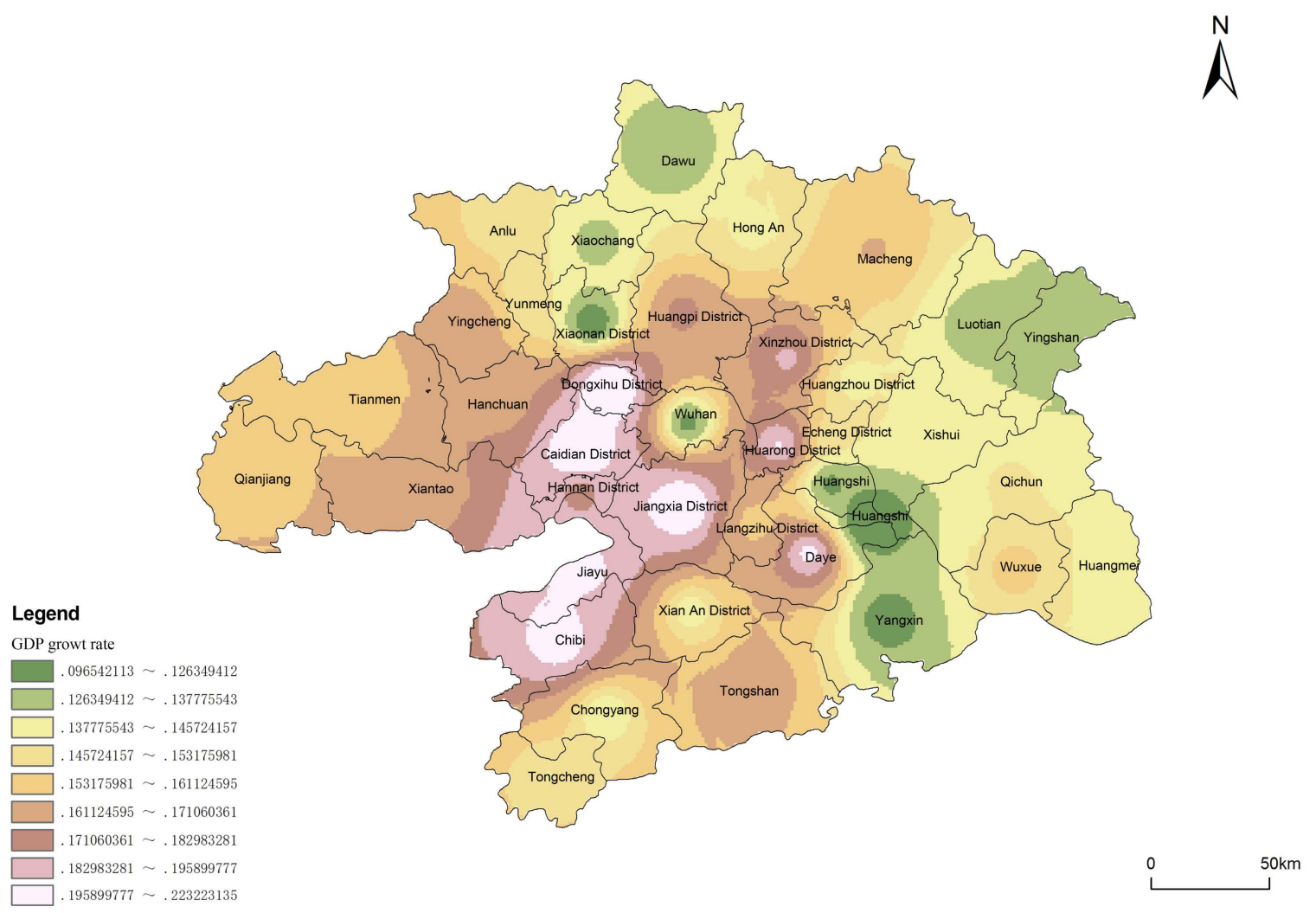

(a)

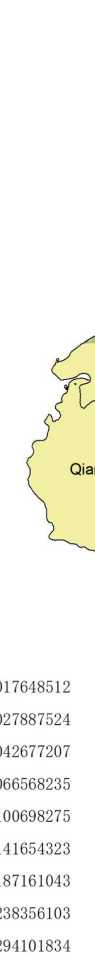

$$
\begin{aligned}
& \text { Legend } \\
& \text { Relative growt rate } \\
& \begin{array}{|l}
\hline \\
\hline \\
\hline \square .003996496 \sim .017648512 \\
.017648512 \sim .027887524 \\
\hline .027887524 \sim .042677207 \\
\hline \square .042677207 \sim .066568235 \\
\hline \square .066568235 \sim .100698275 \\
\hline \square .100698275 \sim .141654323 \\
.141654323 \sim .187161043 \\
\hline \square .187161043 \sim .238356103 \\
\hline \square .238356103 \sim .294101834
\end{array}
\end{aligned}
$$

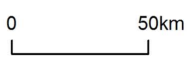

(b)

Figure 7. The analysis of Wuhan Urban Agglomeration economic cold-hot zone with average annual growth rate and relative development rate. (a) GDP growth rate; (b) Relative growth rate. 
This paper further carried out the significance level LISA analysis on two indicators-average annual growth rate and relative development rate (NICH) and identifies the growth agglomeration partition of Wuhan urban agglomeration (Figure 8).

In terms of average annual growth rate, Wuhan urban agglomeration formed the high-high agglomeration area, high-low agglomeration area and low-high agglomeration area from 2009 to 2015, namely, growth diffusion area, growth polarization area and growth subsidence area. The growth diffusion area is located in the middle parts (Jiangxia District, Hanjiang District and Caidian Dis-

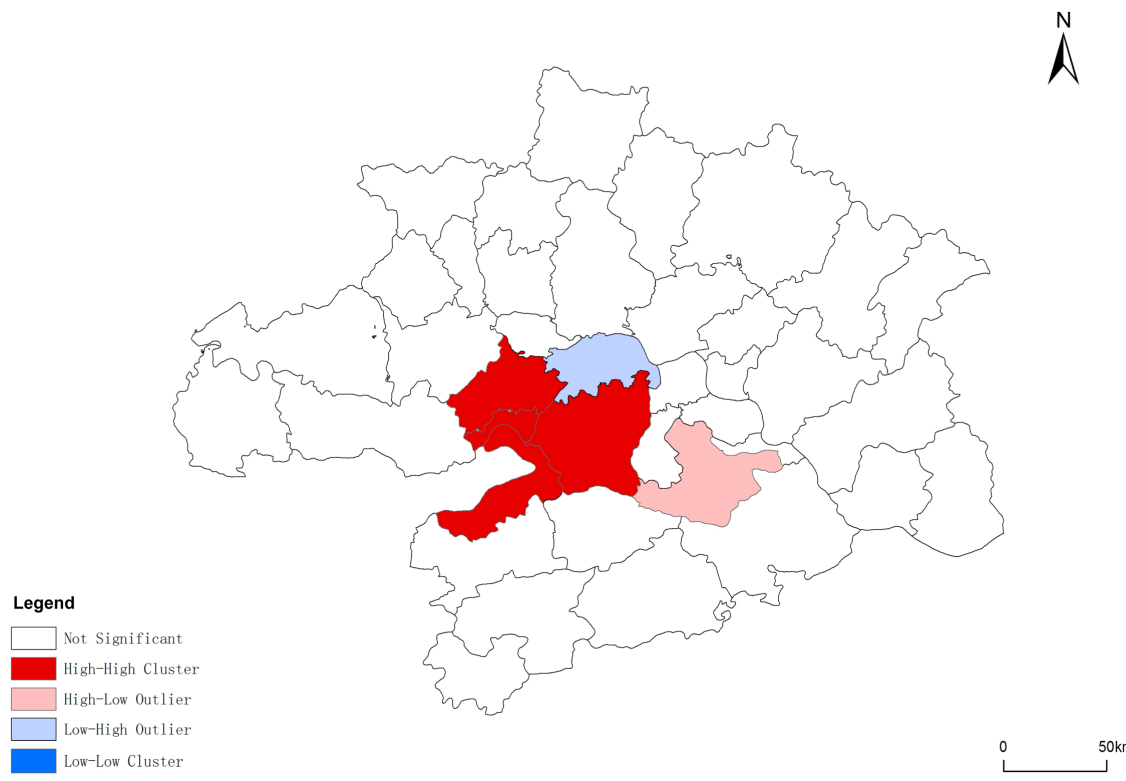

(a)

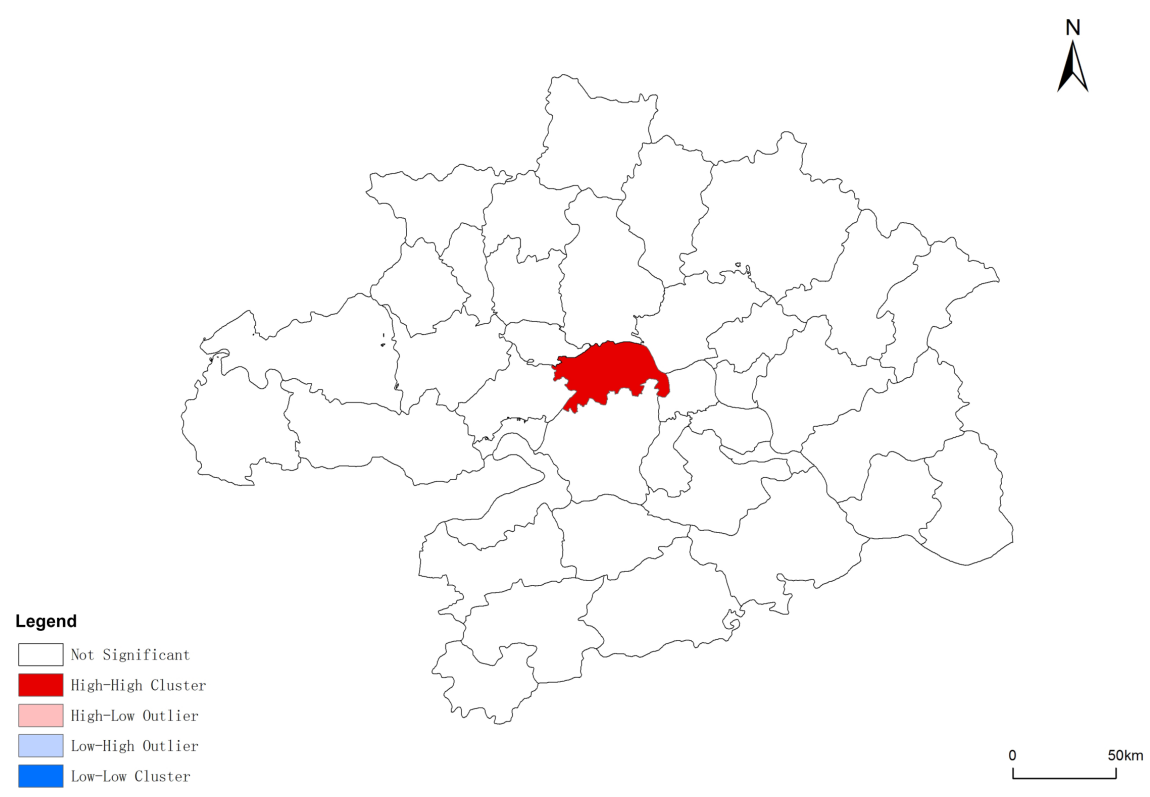

(b)

Figure 8. Economic growth cluster districts of Wuhan Urban Agglomeration. (a) Annual growth rate; (b) Relative growth rate. 
trict under the jurisdiction of Wuhan, as well as Jiayu County under the jurisdiction of Xianning); Growth polarization area is located in Daye under the jurisdiction of Huangshi; The growth subsidence area is located in Wuhan municipal district, indicating that the surrounding growth of this area is faster.

In terms of relative development rate, Wuhan city circle only formed the high-high agglomeration area from 2009 to 2015, namely, growth diffusion area. It is worth noting that there is only one growth diffusion area, namely, Wuhan municipal district, which indicates that though the average annual growth of Wuhan municipal district is slow, yet its relative development rate is far more than that of other cities and counties.

\section{Conclusions and Discussion}

1) General characteristics of urban spatial distribution of Wuhan urban agglomeration present the core-edge structure with relatively dense core and relatively sparse edge. Wuhan and Xianning, Xiaogan, Ezhou and Huangshi gradually gather into the core urban concentration area. Meanwhile, the surrounding space joints also develop constantly and form several sub-regional spaces, presenting the radial core urban concentration area.

2) The spatial correlation of Wuhan urban agglomeration is significant, and its urban land has the characteristic of shaft-driven linear expansion "along river" and "along road". With Wuhan as the center, six radial transportation corridors eastwards, westwards, southwards, northwards, northeastwards and northwestwards are formed to connect various city and town clusters.

3) In 2009-2013, the spatial extension of Wuhan urban agglomeration was mainly concentrated on the western cities and presented the characteristic of first moving towards northwest and then towards southwest. In 5 years, the urban space of Wuhan urban agglomeration presents the trend of expanding year by year, but its growth range is smaller. The core of urban agglomeration has the local fluctuations, but it is still located in the urban area of Wuhan.

4) The overall development pattern of Wuhan urban agglomeration presents the imbalance characteristic of "one predominant core, stronger in the west than the east". At present, the economic development of various counties and cities in the agglomeration area is still at the stage of competition being stronger than cooperation. The developed economic areas are located in Wuhan municipal district and Wuhan-Ezhou-Huangshi-Huanggang urban concentration area, while the economically backward areas are located in the east of Wuhan city circle.

5) Wuhan urban agglomeration formed three growth agglomeration areasgrowth diffusion area, growth polarization area and growth subsidence area from 2009 to 2015. The economic growth ability of Wuhan is relatively strong, and its role in driving the surrounding hinterland areas is also quite significant. Cities along the Yangtze River area such as Qianjiang, Xiantao, Hanchuan, etc. also have better economic growth ability. However, the development speed of Dawu County, Xiaochang County, Yingshan County, Luotian County and other counties in the northeast and southeast regions of urban agglomeration is slower. 
Based on the above results, the further optimization of spatial pattern of $\mathrm{Wu}$ han urban agglomeration should not only emphasize the clustering of Wuhan and its surrounding areas, but also further improve the coordination of hierarchical sub-regional space and overall space. It should focus on enhancing the driving role of core node cites, strengthen the economic relation, improve the economic strength of the county spatial unit, and gradually narrow the economic difference inside Wuhan urban agglomeration.

\section{Support}

This study research is supported by Science and Technology Support Project of Hubei Province (No. 2015BDF040).

\section{References}

[1] Wu, J.S., Liu, H., Peng, J., et al. (2014) Hierarchical Structure and Spatial Pattern of China's Urban System: Evidence from DMSP/OLS Nightlight Data. Acta Geographica Sinica, 69, 760-770.

[2] Shang, Z.Y. and Zhang, X.L. (2009) Urban System Spatial Structure and ITS Fractal Characteristic of the Yangtze Delta. Economic Geography, 29, 913-928.

[3] Liu, L.P. and Mu, G.S. (2011) Analysis of the Structure and Spatial Relation of Zhongyuan City Agglomeration. Areal Research and Development, 30, 165-168.

[4] Small, C., Pozzi, F. and Elvidge, C.D. (2005) Spatial Analysis of Global Urban Extent from DMSP-OLS Night Lights. Remote Sensing of Environment, 96, 277-291. https://doi.org/10.1016/j.rse.2005.02.002

[5] Li, Z., Qiang, L., Jin, C., et al. (2007) Characteristics Analysis of Urban Land Expansion in China in 1990s Using DMSP/OLS Data. Acta Scientiarum Naturalium Universitatis Sunyatseni, 3, 98-102.

[6] Lu, D., Tian, H., Zhou, G. and Ge, H. (2008) Regional Mapping of Human Settlements in Southeastern China with Multisensor Remote Sensed Data. Remote Sensing of Environment, 112, 3668-3679. https://doi.org/10.1016/j.rse.2008.05.009

[7] Cao, X., Chen, J., Imura, H. and Higashi, O. (2009) A SVM-Based Method to Extract Urban Areas from DMSP-OLS and SPOT VGT Data. Remote Sensing of Environment, 113, 2205-2209. https://doi.org/10.1016/j.rse.2009.06.001

[8] Elvidge, C.D., Baugh, K.E., Kihn, E.A., et al. (1997) Relation between Satellite Observed Visible-Near Infrared Emissions, Population, Economic Activity and Electric Power Consumption. International Journal of Remote Sensing, 18, 1373-1379. https://doi.org/10.1080/014311697218485

[9] Elvidge, C.D., Imhoff, M.L., Baugh, K.E., et al. (2001) Night-Time Lights of the World: 1994-1995. ISPRS Journal of Photogrammetry and Remote Sensing, 56, 81 99. https://doi.org/10.1016/S0924-2716(01)00040-5

[10] He, C., Shi, P., Li, J., et al. (2006) Spatial Restruction of Urbanization in Chinese Mainland in 1990s Using DMSP/OLS Night Light Data and Statistical Data. Chinese Science Bulletin, 51, 856-861. https://doi.org/10.1007/s11434-006-2006-3

[11] Raupach, M., Rayner, P. and Paget, M. (2009) Regional Variations in Spatial Structure of Nightlights, Population Density and Fossil-Fuel $\mathrm{CO}_{2}$ Emissions. Energy Policy, 38, 4756-4764. https://doi.org/10.1016/j.enpol.2009.08.021

[12] Chalkias, C., Petrakis, M., Psiloglou, B. and Lianou, M. (2006) Modelling of Light Pollution in Suburban Areas Using Remotely Sensed Imagery and GIS. Journal of 
Environmental Management, 79, 57-63.

https://doi.org/10.1016/j.jenvman.2005.05.015

[13] Wang, Y.Y., Xu, D. and Zhu, X.G. (2010) The Spatio-Temporal Characteristics of Urban and Town Construction Land Expansion in Jiangsu Province from DMSPOLS Nighttime Images. Modern Urban Research, No. 2, 67-73.

[14] Liao, B., Wei, K.X. and Song, W.W. (2012) Assessment and Application of DMSP/ OLS Night Time Light Data in Spatial Structure of Urban System-A Case of Jiangxi Province in Nearly 16 Years. Resources and Environment in the Yangtze Basin, 21, 1297-1300.

[15] Xu, M.J., Chen, L., Liu, H.J., et al. (2011) Pattern and Process of Urbanization in the Yangtze Delta Based on DMSP/OLS Data. Remote Sensing for Land \& Resources, No. 9, 107-112.

[16] Change, T. and Wu, S.H. (2014) Spatial-Temporal Characteristics of Yangtze River Delta Urban Agglomeration's Geographic Expansion in Recent Decades-An Empirical Study Based on DMSP/OLS Night Light Data. Modern Urban Research, No. 7, 67-72.

[17] Zhang, C., Wang, C.Y., Lv, Y.Q., et al. (2015) Research on City System Spatial Structure of the Yangtze River Economic Belt: Based on DMSP/OLS Night Time Light Data. Urban Development Studies, 22, 19-26.

[18] Liu, J.S. and Chen, Y.G. (1999) Fractal Dimensions of Spatial Structure of an Urban System and the Methods of Their Determination. Geographical Research, 18, 172 178.

[19] Wang, C.Y., Wu, G.Y. and Zhang, C. (2015) Research on Spatial Structure of the Chengdu-Chongqing Urban Agglomeration Based on the DMSP/OLS Night Time Light Data. Urban Development Studies, 22, C20-C24.

[20] Gangopadhyay, K. and Basu, B. (2009) City Size Distribution for India and China. Physica A: Statistical Mechanics and Its Applications, 388, 2682-2688. https://doi.org/10.1016/j.physa.2009.03.019

[21] Liu, J.S. and Chen, Y.G. (1999) A Study on Fractal Dimensions of Spatial Structure of Transport Networks and the Methods of Their Determination. Acta Geographica Sinica, 54, 472-477.

[22] Shang, Z.Y. and Zhang, X.L. (2009) Urban System Fractal Characteristic of the Yangtze Delta Interlocking Metropolitan Areas. Resources and Environment in the Yangtze Basin, 18, 998-1002.

[23] Song, J.C., Li, X.H., Lin, T., et al. (2015) A Method of Extracting Urban Built-Up Area Based on DMSP/OLS Nighttime Data and Google Earth. Journal of Geo-Information Science, 17, 750-756. 
Submit or recommend next manuscript to SCIRP and we will provide best service for you:

Accepting pre-submission inquiries through Email, Facebook, LinkedIn, Twitter, etc. A wide selection of journals (inclusive of 9 subjects, more than 200 journals)

Providing 24-hour high-quality service

User-friendly online submission system

Fair and swift peer-review system

Efficient typesetting and proofreading procedure

Display of the result of downloads and visits, as well as the number of cited articles Maximum dissemination of your research work

Submit your manuscript at: http://papersubmission.scirp.org/

Or contact jbcpr@scirp.org 